\title{
AN EXTERNAL BEAM TECHNIQUE OF PIXE FOR URANIUM DETERMINATION IN ENVIRONMENTAL OBJECTS
}

\author{
V.V. Kuzmenko, V.V. Levenets, O.P. Omelnik, I.L. Rolik, A.O. Shchur \\ National Science Center "Kharkov Institute of Physics and Technology", Kharkiv, Ukraine \\ E-mail: levenets@kipt.kharkov.ua
}

The possibilities of the determination of the content of uranium in materials of the nuclear fuel cycle and environmental objects using the nuclear-physical methods of analysis based on registration of characteristic X-rays excited by protons (PIXE) are considered. It is shown that the introduction to X-ray emission spectrometer the element with a wave dispersion - a pyrocarbon filter, using Bragg-Wulf reflection from the planes of the crystal lattice, makes it possible to reduce the detection limit of uranium in the presence of interfering impurities to a value of 0.0005 mas.\%. The proposed approach can be used to determine $\mathrm{Th}, \mathrm{Pu}$, and other actinides.

\section{INTRODUCTION}

The development of high-tech industries, and the associated with it the increase in the influence of anthropogenic factors, require the introduction and improvement of systems for controlling the accumulation and the spread of substances that may affect adversely to the state of the environment and human health. These concerns, to a large extent, of the nuclear power industry, whose contribution to the overall balance of electricity production in recent years has reached more than 50 percent. The operation of nuclear power plants (NPPs) requires of the organization of the monitoring of the contents, in the plant rooms and in the adjacent territories, of a group of elements, which are formed as a result of the splitting of the nuclei of uranium atoms and uranium itself, as the main element of the nuclear fuel cycle. In addition, the uranium content in the production wastes at various stages of uranium ore mining and processing, production, operation and recycling of spent fuel elements is subject to control.

Taking into account the peculiarities of the technological processes involved in the nuclear fuel cycle, it is necessary to determine the content of uranium in atmospheric air, water, bottom sediments, soils, dumps of mining and processing plants, etc. The range of uranium concentrations in samples can vary from thousandths to tens of mass percent. The content of the main components also varies in wide ranges.

Therefore, to determine the uranium content, it is advisable to use a universal method that does not require of the complex sample preparation, can be automated for experimental measurements and the processing of the data obtained. It is also preferable to use a method that allows, if necessary, to use an external standard method or a method of fundamental parameters for calculating of the uranium concentration, to evaluate the influence on the determination of uranium of other elements present in the sample substance and does not require the use of a large amount of substance. In addition, the analysis should not lead to the destruction of the sample, the accumulation of radioactive or chemically dangerous elements. The analysis procedure should have the tools to optimize the determination of uranium in the presence of elements, that create the difficulties to allocate the analytical signal, and the analysis itself, if necessary, can be performed in atmospheric air, outside of special vacuum chambers.

It is proposed, taking into account this set of requirements for the analysis, to use the modifications of PIXE for the determination of uranium content. This method is based on the registration of characteristic Xrays excited by a beam of heavy accelerated ions, generated by electrostatic accelerators [1]. It can be used:

- with the placement of the irradiated object in a vacuum chamber;

- with the "external" ion beam - irradiation of the samples into the atmosphere;

- with registration characteristic X-rays directly by $\mathrm{Si}(\mathrm{Li})$ or Si-pin semiconductor detectors;

- with registration characteristic X-rays after their passing through an element with wave dispersion.

The aim of the work is the development and implementation of method for determining the uranium content at the level of $0.0005 \ldots 0.75$ mas.\% in the samples, that characterize the operation of enterprises of nuclear fuel cycle, to ensure control over its localization at the stages of extraction, processing, operation, utilization and long-term storage of spent fuel.

\section{EXPERIMENTAL MEASUREMENTS}

All experimental measurements were made on analytical nuclear-physical complex "Sokol" NSC KIPT [2].

\section{DETERMINATION OF CONTENT OF URANIUM USING ROUTINE PIXE}

Determination of the elemental content of the substance, using the routine PIXE, is based on the registration of protons induced X-ray emission of sample by the energy dispersive detector with a crystal from silicon or germanium. Mostly the irradiation of target is carried out in vacuum.

In order to evaluate the features of the routine PIXE analysis to determine the content of uranium in nuclear fuel cycle samples, experimental measurements of the $\mathrm{X}$-ray spectra were carried out for a series of objects containing uranium at the level of $0.03 \ldots 0.13 \mathrm{wt} \%$. The substances of the samples were the product of the processing of uranium ore.

The targets were made from these samples as compressed tablets weighing $100 \ldots 200 \mathrm{mg}$, of $9 \mathrm{~mm}$ in 
diameter and $2 \mathrm{~mm}$ thickness. For studying of elemental content the targets were placed in vacuum chamber and irradiated by a protons beam with an energy of $1000 . .1500 \mathrm{keV}$ and a current of $100 . .500 \mathrm{nA}$. I was found that the optimal conditions of analysis are achieved at a proton energy of $1400 \mathrm{keV}$ and beam current of $200 \mathrm{nA}$. The time of measurement of one spectrum was $500 \mathrm{~s}$.

Table shows the elemental content of the samples under study, which was determined, using the routine PIXE and PIGE (proton induced $\gamma$-emission from nuclear reaction)

The content of $\mathrm{Na}, \mathrm{Li}, \mathrm{O}, \mathrm{Mg}, \mathrm{Al}, \mathrm{F}$ was determined by the PIGE based on the detection of $\gamma$-radiation from nuclear reactions of the type $(p, \gamma),\left(p, p^{\prime} \gamma\right),(p, \alpha \gamma)$ excited by protons on the nuclei of atoms of isotopes of these elements.

The content of the remaining elements was determined by the routine PIXE. To determine the content of elements from $\mathrm{Si}$ to $\mathrm{Zr}$, characteristic X-rays of K-series, and for determination content of $\mathrm{Pb}$ and $\mathrm{U}-$ characteristic X-rays of L-series was used.

The elemental content of the studied samples is typical for products of processing of uranium ore and corresponds to the expected content of samples used for environmental monitoring of objects of the fuel and energy cycle.

From the elements, which were determined in the studying samples, the closest values towards the energy of the analytical line $\mathrm{L}_{\alpha 1}$-series $\mathrm{U} 13.62 \mathrm{keV}$ have the line of $\mathrm{K}_{\alpha 1}$-series of $\mathrm{Rb}-13.39 \mathrm{keV}$, and $\mathrm{Sr}-$
$14.16 \mathrm{keV}$. The energy resolution of the Si-pin detector is $150 \mathrm{eV}$ and allows you to confidently separate the peaks from these three elements, but characteristic $\mathrm{X}$-rays emission from $\mathrm{Rb}$ and $\mathrm{Sr}$ makes a significant contribution to the background, under the peak of uranium, which leads to a deterioration of the conditions for its determination in a similar matrix.

Quantitatively, these conditions are characterized by an estimate of the limit of determination (LD) - the minimum possible concentration of the element under study in a particular matrix, which can be reliably determined by the chosen method of analysis. The limit of determination is a semi-quantitative characteristic of the method, allowing to evaluate its sensitivity relative to the determination of the content of the element. According to statistical standards, the commonly used characteristic of the reliability of analysis results is the $3 \sigma$ criterion, and the limit of determination is calculated using the formula (1)

$$
L D=\frac{C}{N} \cdot 3 \cdot \sigma,
$$

where $C-$ is the content of the element being determined in the reference sample; $N$ - is the sum of the pulses at the peak of the analytical line of the element being determined in the reference sample; $\sigma-$ is the standard deviation of the background level for the peak of the analytical line of the element being determined, which is estimated by approximating the background level to the left and right of the peak.

The elemental content of the studied samples of uranium, mas. \%

\begin{tabular}{|c|c|c|c|c|c|}
\hline $\begin{array}{c}\text { Ele- } \\
\text { ments }\end{array}$ & No 1 & No 2 & No 3 & No 4 & No 5 \\
\hline $\mathrm{Si}$ & $34.72 \pm 0.87$ & $31.91 \pm 0.75$ & $34.05 \pm 0.81$ & $44.43 \pm 0.93$ & $34.97 \pm 0.67$ \\
\hline $\mathrm{Na}$ & $8.39 \pm 0.01$ & $6.82 \pm 0.03$ & $7.98 \pm 0.07$ & $9.67 \pm 0.06$ & $0.21 \pm 0.01$ \\
\hline $\mathrm{Li}$ & $0.0010 \pm 0.0002$ & $0.0011 \pm 0.0002$ & $0.0014 \pm 0.0001$ & $0.0021 \pm 0.0001$ & - \\
\hline $\mathrm{O}$ & $34.58 \pm 4.47$ & $42.98 \pm 3.91$ & $28.64 \pm 10.46$ & $16.75 \pm 1.67$ & $44.06 \pm 5.00$ \\
\hline $\mathrm{Mg}$ & $0.72 \pm 0.04$ & $0.54 \pm 0.14$ & $0.77 \pm 0.32$ & $0.53 \pm 0.17$ & $0.04 \pm 0.02$ \\
\hline $\mathrm{Al}$ & $6.69 \pm 0.37$ & $5.28 \pm 0.23$ & $8.21 \pm 0.10$ & $9.81 \pm 0.12$ & $1.24 \pm 0.09$ \\
\hline $\mathrm{F}$ & $0.046 \pm 0.002$ & $0.036 \pm 0.002$ & $0.052 \pm 0.005$ & $0.056 \pm 0.001$ & $0.010 \pm 0.000$ \\
\hline $\mathrm{Ca}$ & $4.92 \pm 0.47$ & $5.20 \pm 0.51$ & $10.99 \pm 0.95$ & $6.12 \pm 0.74$ & $14.68 \pm 0.65$ \\
\hline $\mathrm{Sc}$ & - & $0.39 \pm 0.49$ & $0.16 \pm 0.57$ & $0.50 \pm 0.76$ & $0.52 \pm 0.39$ \\
\hline $\mathrm{Ti}$ & $1.33 \pm 0.13$ & $1.06 \pm 0.12$ & $1.23 \pm 0.14$ & $1.31 \pm 0.18$ & $1.45 \pm 0.11$ \\
\hline $\mathrm{V}$ & $0.23 \pm 0.04$ & $0.14 \pm 0.03$ & $0.13 \pm 0.04$ & $0.20 \pm 0.05$ & $0.28 \pm 0.03$ \\
\hline $\mathrm{Cr}$ & $0.06 \pm 0.01$ & $0.05 \pm 0.01$ & $0.04 \pm 0.01$ & $0.04 \pm 0.01$ & $0.03 \pm 0.00$ \\
\hline $\mathrm{Mn}$ & $0.87 \pm 0.02$ & $0.62 \pm 0.02$ & $0.66 \pm 0.02$ & $0.78 \pm 0.02$ & $0.37 \pm 0.01$ \\
\hline $\mathrm{Fe}$ & $7.07 \pm 0.02$ & $5.25 \pm 0.02$ & $6.68 \pm 0.02$ & $8.80 \pm 0.02$ & $1.97 \pm 0.01$ \\
\hline $\mathrm{Ni}$ & $0.056 \pm 0.003$ & $0.038 \pm 0.002$ & $0.007 \pm 0.001$ & $0.525 \pm 0.050$ & $0.002 \pm 0.001$ \\
\hline $\mathrm{Cu}$ & $0.062 \pm 0.003$ & $0.039 \pm 0.002$ & $0.004 \pm 0.001$ & $0.020 \pm 0.002$ & $0.003 \pm 0.001$ \\
\hline $\mathrm{Zn}$ & $0.073 \pm 0.003$ & $0.047 \pm 0.002$ & $0.015 \pm 0.002$ & $0.032 \pm 0.002$ & $0.001 \pm 0.001$ \\
\hline $\mathrm{As}$ & - & - & - & $0.003 \pm 0.000$ & $0.002 \pm 0.001$ \\
\hline $\mathrm{Rb}$ & 0.0102 & 0.006 & 0.0078 & 0.0064 & 0.0005 \\
\hline $\mathrm{Sr}$ & $0.076 \pm 0.008$ & $0.151 \pm 0.008$ & $0.132 \pm 0.004$ & $0.147 \pm 0.002$ & $0.020 \pm 0.001$ \\
\hline $\mathrm{Y}$ & - & $0.004 \pm 0.006$ & $0.026 \pm 0.002$ & $0.014 \pm 0.003$ & $0.011 \pm 0.002$ \\
\hline $\mathrm{Zr}$ & $0.092 \pm 0.006$ & $0.135 \pm 0.008$ & $0.125 \pm 0.006$ & $0.136 \pm 0.003$ & $0.105 \pm 0.002$ \\
\hline $\mathrm{Pb}$ & $0.015 \pm 0.005$ & $0.009 \pm 0.002$ & $0.008 \pm 0.000$ & $0.017 \pm 0.000$ & $0.001 \pm 0.000$ \\
\hline $\mathrm{U}$ & $0.107 \pm 0.007$ & $0.060 \pm 0.006$ & $0.090 \pm 0.007$ & $0.126 \pm 0.002$ & $0.026 \pm 0.001$ \\
\hline
\end{tabular}


The values of $\sigma$ and $\mathrm{N}$ are calculated directly during the processing of the spectrum, and, as can be seen from formula (1), the detection limit is the smaller, the smaller the value of $\sigma$ and more $N$. To reduce the limit of determination, you must either increase $N$, which leads to an increase in the charge of protons on the target and entails an increase in the current or time of measurement of the spectrum, or reduce the value of $\sigma$, which requires modification of the spectrum of characteristic X-rays so as to reduce the background level to the left and right side of the peak.

Accordantly to calculations, $L D$ of uranium is $0.0027 \mathrm{mas} . \%$ for the protons energy $1400 \mathrm{keV}$, the beam current $200 \mathrm{nA}$ and the charge accumulated on the target $600 \mu \mathrm{C}$. The reducing this value several times, to the level of 0.0005 mas.\%, which as it is estimated to be enough to monitor the uranium content in environmental objects, requires a qualitatively new approach aimed at a significant improvement in the signal-to-background ratio for the analytical line of uranium. This can be achieved by reducing the background in the energy range of quanta $13 \ldots 15 \mathrm{keV}$, while maintaining the intensity of the radiation of X-ray of $\mathrm{L}_{\alpha 1}$-series of $\mathrm{U}$.

In order to achieve a similar effect, it is necessary to introduce into the spectrometric scheme of registration of radiation an element with dispersion relative to the wavelength of quantum - the X-ray Filter based on Pyrolytic Graphite (PGF), which in the X-ray optical scheme performs the function of a crystalmonochromator using the Bragg X-ray reflection from the planes of the crystal lattice [3]. Previously, this approach was used by the authors to optimize the determination of iron and hafnium in zirconium [3, 4].

\section{EXPERIMENTAL MEASUREMENTS ON AN EXTERNAL PROTONS BEAM WITH A PYROLYTIC GRAPHITE FILTER}

For selective transmission of X-ray radiation from the objects under study, the detector used PGF in the form of a cylindrical assembly of plane-parallel pyrolytic carbon plates $3 \times 1 \times 36 \mathrm{~mm}$ in sizes. These plates were cut along the plane of the reflecting surface with the (002) orientation, with a mosaic pattern of $0.5 \AA$ and a lattice constant of $6.619 \AA$. The central part of the filter is covered with a thick foil, which prevents radiation from entering the detector directly from the target. At the same time, the filter focuses the X-rays, reflected from the crystal plates at a certain angle, by varying which a significant decrease in the background value takes place at the location of the analytical line $\mathrm{L}_{\alpha 1^{-}}$ series of U. Schematically the filter is shown in Fig. 1

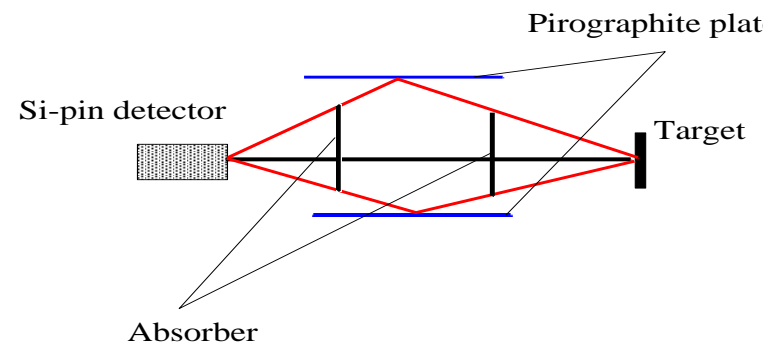

Fig. 1. Schematic representation of the $X$-ray filter from pyrolytic graphite
PGF should be located between the detector and the target at a distance of a few centimeters, varying depending on the energy of the line for which the measurement conditions are optimized. The great filter dimensions and the need to change the detector-PGF and PGF-target distances with high accuracy make it impossible to perform the analysis in a vacuum chamber. Therefore an accelerator channel with an "external beam" was used, in which the beam was went out into the atmosphere through a window from aluminum foil of $7 \mu \mathrm{m}$ thick

In Fig. 2 a scheme shows for measuring the spectra of X-rays emission induced by external protons beam with spectrometer including PGF.

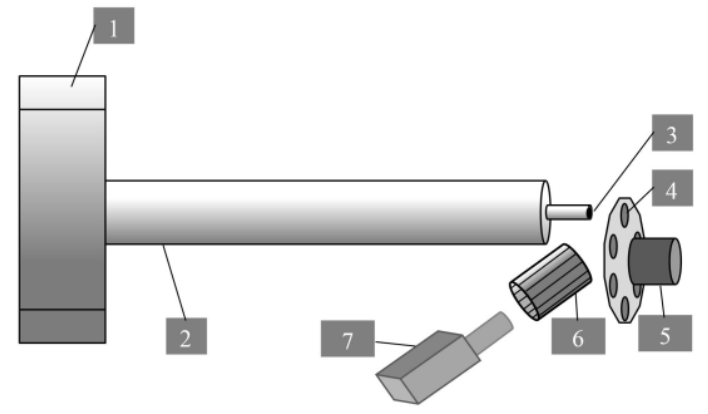

Fig. 2. Scheme of the experimental setup with PGF in the spectrometric channel:

1 -distribution magnet; 2 - ion conduit; 3 -window of the output of protons beam into the atmosphere;

4 -target; 5 -device for the movement of targets; 6-PGF; 7 - Si-pin X-ray detector

The detector and the PGF were located on the platform, which provided the possibility of their movement at a given distance with an accuracy of $1 \mathrm{~mm}$ relative to the target and relative to each other. The platform also allows to displace detector and filter in the transverse direction so that the axis of the filter was coincided with the direction of the target-detector

\section{RESULTS AND DISCUSSION}

Some samples with known uranium content were made on the basis of a reference soil specimens, and the series of measurements were carried out, using these samples, to identify the optimal conditions for the determination of uranium in soil at a level from 0.0005 to 0.5 mas. $\%$. The uranium content in the samples under study was $0.96,0.41,0.038$, and 0.0055 mas. $\%$. In the studying samples the substance of the reference soil sample was about $94 \ldots 95$ mas. \% and about 5...6 mas.\% accounted for powdered carbon, which was introduced to improve the electrical conductivity of target under proton beam. Three samples were made for each value of uranium concentration. Two series of studies were carried out for these samples: the first - using the traditional PIXE with energy dispersive detector, and the second - using on the external beam with wave dispersive scheme for X-ray spectrometer (PIXE + PGF).

During the measurements using the traditional PIXE, the targets were placed in vacuum chamber and irradiated by the protons beam with energy $1400 \mathrm{keV}$ and current of $600 \mathrm{nA}$. The charge of protons on the target was varied from 100 to $1000 \mu \mathrm{C}$, depending on 
the uranium content in the sample. The purpose of the study was to check the quality of the fabrication of reference samples for uranium content and to study the dependence of the radiation intensity from uranium content for characteristic X-ray analytical line. 12 reference samples were examined for each from them 5 parallel measurements of the spectra of characteristic Xray emission were performed. The results of the determination the sum of the pulses at the peak of the analytical line were averaged for each of samples with different values of content of uranium, the data obtained were normalized to a charge of $100 \mu \mathrm{C}$. Fig. 3 shows the dependence of the number of pulses on the uranium content in the reference samples.

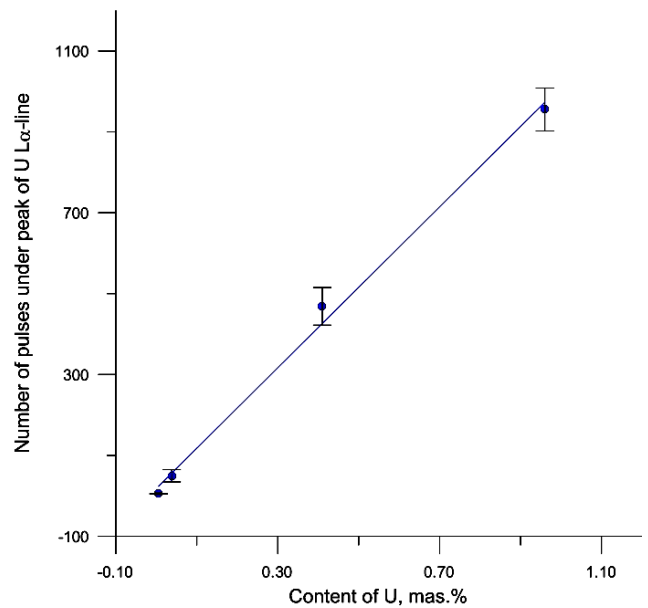

Fig. 3. Dependence of the sum of pulses at the peak of the $L_{\alpha 1}$-series $U$ on the content of $U$ in the reference samples

The error of measurement results is the average deviation for a series of 15 measurements for three samples of 5 spectra of characteristic X-ray emission for each. This error simultaneously takes into account the systematic errors associated with the operation of the accelerator, the spectrometric tract, the current beam integrator and the errors associated with the production of reference samples. In particular, errors of the weighting and the possible inhomogeneity of the substance of the reference samples, which could have occurred when small amounts of uranium were introduced and mixed in substantially large volumes of the base material. As can be seen from Fig. 3 data, the dependence is linear within the experimental errors. This testifies to the high quality of manufacturing of reference samples, the stability of the accelerator and spectrometer, as well as the possibility of calculating the uranium content in the samples under study by the external reference method in a range of concentrations that differ by $2-3$ orders of magnitude.

The reference sample with 0.96 mas.\% of content of uranium was used to optimize the X-ray registered scheme during the using of PIXE with PGF on the external protons beam. Experimentally it was found, that the best signal-to-background ratio for the analytical line of $\mathrm{L}_{\alpha 1}$-series of $\mathrm{U}$ is achieved at the target-PGF and target-detector distances of 132 and $66 \mathrm{~mm}$ respectively. For these geometrical conditions a serie of measurements of spectra of characteristic X-ray emission for reference samples was performed. These samples have content of uranium in the range of $0.0055 \ldots 0.96$ mas.\%. The initial proton energy was $1600 \mathrm{keV}$. On the target, taking into account the loss of protons energy in the foil of the output window of the beam into the atmosphere and in layer of atmospheric air of $5 \mathrm{~mm}$ thickness, the protons had an energy about $1400 \mathrm{keV}$. The protons beam current on the target was $400 \mathrm{nA}$, the charge accumulated on the target during measurement of spectrum was varied from 500 to $3000 \mu \mathrm{C}$, depending on the uranium content.
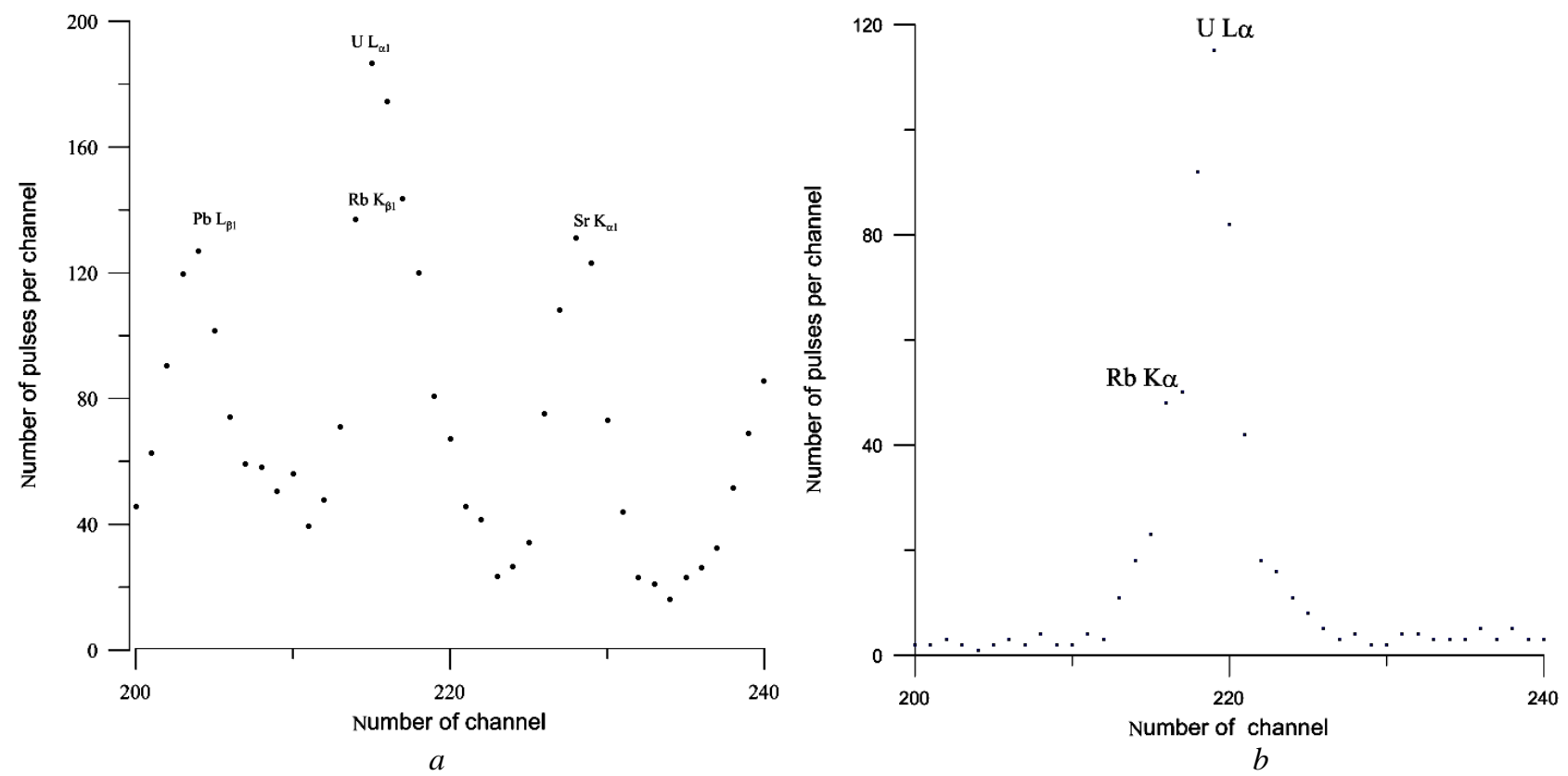

Fig. 4. The X-ray spectra of the reference sample with different schemes of registration of emission.

Content of uranium $-0.038 \%$, energy of protons on a target $-1400 \mathrm{keV}$; $a-$ Traditional PIXE, $b-P I X E+P G F$ 
Fig. 4 shows the spectra of characteristic X-ray emission of reference sample with an uranium content of 0.038 mas.\%, which was obtained using traditional PIXE with registration of radiation from a target directly with a Si-pin detector - Fig. 4,a, and the spectrum of characteristic X-ray emission of the same sample modified with the help of PGF using the PIXE+PGF method on the external beam - Fig. 4,b.

As can be seen from the spectrum fragments shown in the Fig. 4, in the range close to the energy of the analytical line of $\mathrm{L}_{\alpha 1}$-series of uranium, the use of PGF leads to the significant decrease in the background level and standard deviation of background intensity. Accordingly, the determination limit calculated by formula (1) decreases.

So the use of PGF leads to the almost complete suppression of the peaks of emission of the $\mathrm{L}_{\alpha}$-series of $\mathrm{Pb}$ and $\mathrm{K}_{\alpha}$-series of $\mathrm{Sr}$, which impede the approximation of the background, and also significantly reduce the intensity of the characteristic X-ray emission the $\mathrm{K}_{\alpha^{-}}$ series of $\mathrm{Rb}$, which, on the one hand, complicates the calculation of the background, and, on the other hand, hinders the reliable assessment of the sum of pulses for the peak of the analytical line of uranium - Fig. 4,a.

The limit of determination of uranium, calculated for measured spectra, fragments of which are shown in Fig. 4, is 0.0027 mas.\% - for the traditional PIXE with an energy dispersive X-ray detection scheme (see Fig. $4, a)$ and - 0.0004 mas. $\%$ - for the PIXE+PGF using wave dispersion of X-ray in the X-ray detection scheme (see Fig. 4,b).

\section{CONCLUSION}

A method has been developed for the determination of low concentrations of uranium in environmental objects and objects, characterizing the different stages of the extraction, processing and storage of uranium ore, the production, the use and disposal of uraniumcontaining products. The studies have shown that the proposed method for determining uranium in objects of the nuclear fuel cycle allows making its monitoring in soils, tailings dumps, bottom sediments, etc. at a level from 0.0005 to 0.75 mas.\%. The limit of determination of uranium is significantly reduced when using an X-ray filter made from pyrolytic graphite with adjustable, relative to the quanta energy, the $\mathrm{X}$-ray transmission band. The proposed method can be modified to determine thorium, plutonium and other elements of the uranium group at a level of 0.0005 mas.\% and above.

\section{REFERENCES}

1. S.A.E. Johansson, T.B. Johansson. Analytical application of particle induced X-ray emission // Nucl. Instr. Meth. 1976, v. 137, p. 473-516.

2. V.N. Bondarenko, L.S. Glasunov, A.V. Goncharov, A.V. Zats, V.V. Kuzmenko, V.V. Levenets, A.P. Omelnik, V.M. Pistryak, V.I. Sukhostavets, A.A. Shchur, N.P. Usikov. NSC KIPT analytical nuclear-physical complex "SOKOL" // International Conference Current Problems of Nuclear Physics and Atomic Energy (NPAE-Kyiv 2006), May 29-June 03, 2006, Kyiv, Ukraine, p. 163.

3. V.V. Levenets, O.P. Omelnyk, A.O. Shchur, E.A. Chernov. The using of PIXE and pyrolytic graphite filter to determine of $\mathrm{Fe}$ in $\mathrm{ZrF} 4 / /$ The Journal of Kharkiv National University physical. Series "Nuclei, Particles, Fields". 2007, N 2(34), p. 84-88.

4. O.P. Omelnyk, V.V. Levenets, A.Yu. Lonin, I.V. Shevchenko, A.O. Shchur. Determination of the Content of Hf in Zirconium Alloys with using a Wide Band X-Ray Emission Filter // Methods and objects of chemical analysis. 2018, v. 13, N 4, p. 153-159.

Article received 12.07.2019

\section{ХРИ НА ВЫПУЩЕННОМ ПУЧКЕ ДЛЯ ОПРЕДЕЛЕНИЯ СОДЕРЖАНИЯ УРАНА В ОБЬЕКТАХ ОКРУЖАЮЩЕЙ СРЕДЫ}

\section{В.В. Кузьменко, В.В. Левенец, А.П. Омельник, И.Л. Ролик, А.А. Щур}

Рассмотрены возможности определения содержания урана в материалах ядерного топливного цикла и объектах окружающей среды с использованием ядерно-физических методов анализа на основе регистрации характеристического рентгеновского излучения, возбуждаемого протонами (PIXE). Показано, что введение в спектрометр рентгеновского излучения элемента с волновой дисперсией - пирографитного фильтра, использующего отражение Брэгга-Вульфа от плоскостей кристаллической решетки, позволяет снизить предел определения урана в присутствии мешающих примесей до значения 0,0005 мас.\%. Предложенный подход может быть использован для определения Th, Pu и других актинидов.

\section{ХРВ НА ВИПУЩЕНОМУ ПУЧКУ ДЛЯ ВИЗНАЧЕННЯ ВМІСТУ УРАНУ В ОБ'ЄКТАХ ДОВКІЛЛЯ}

\section{В.В. Кузьменко, В.В. Левенець, О.П. Омельник, І.Л. Ролік, А.О. Щур}

Розглянуто можливості визначення вмісту урану в матеріалах ядерного паливного циклу та об'єктів навколишнього середовища 3 використанням ядерно-фізичних методів аналізу на основі реєстрації характеристичного рентгенівського випромінювання, збуджуваного протонами (РIXЕ). Показано, що введення у спектрометр рентгенівського випромінювання елемента 3 хвильовою дисперсією пірографітного фільтра, що використовує віддзеркалення Брегга-Вульфа від площин кристалічної решітки, дозволяє знизити межу визначення урану в присутності домішок, що заважають, до значення 0,0005 мас.\%. Запропонований підхід може бути використаний для визначення $\mathrm{Th}, \mathrm{Pu}$ та інших актинідів. 